\title{
The Large-Scale Movement of Saharan Air Outbreaks over the Northern Equatorial Atlantic ${ }^{1}$
}

\author{
TOBY N. CARLSON \\ National Hurricane Research Laboratory, NOAA, Miami, Fla. 33124 \\ And Joseph M. Prospero \\ University of Miami, Rosenstiel School of Marine and Almospheric Science, Miami, Fla. 33149
}

(Manuscript received 20 July 1971)

\begin{abstract}
The intense and prolonged heating of air passing over the Sahara during the summer and early fall months forms a deep mixed layer which extends up to 15-20,000 ft during July, the warmest month. The dust-laden heated air emerges from West Africa as a series of large-scale anticyclonic eddies which move westward over the tropical Atlantic above the trade-wind moist layer, principally in the layer between 5000 and $15,000 \mathrm{ft}$ $(600-800 \mathrm{mb})$. Measurements made during BOMEX show that this Saharan air is characterized by high values of potential temperature, dust and radon-222 which confirm a desert origin. As the parcels of air within the layer proceed across the Atlantic the continuous fallout of particulate matter and the mixing at the base of the layer cause dust to be transferred to the lower levels where its concentration may become sufficiently great to produce dense haze at the surface over wide areas over the Atlantic and Caribbean in the latitude belt $10-25 \mathrm{~N}$. Nevertheless, measurements indicate that the dust concentration and associated haziness are greater at $10,000 \mathrm{ft}$ than at the surface.

The presence of Saharan air over the Caribbean can be recognized on conventional meteorological soundings as a virtually isentropic layer within which the potential temperature is about $40 \mathrm{C}$; the mixing ratio within this layer generally remains fairly constant with height with typical mean values of $2-4 \mathrm{gm} \mathrm{kg}^{-1}$. The upper surface of the Saharan air layer, clearly visible from above as a sharply defined haze top, coincides with an inversion, above which the mixing ratio decreases rapidly with height. The lower portion of the isentropic Saharan air layer may be as much as 5-6C warmer than the normal tropical atmosphere; consequently, there is a strong suppressive inversion above the moist trade-wind layer. There is also a sharp horizontal temperature gradient between the Saharan dust plume and the normal tropical air mass; aircraft penetrations into Saharan air at heights of $700-800 \mathrm{mb}$ show that the discontinuity between Saharan and non-Saharan air is front-like in character inasmuch as the potential temperature and mixing ratio may change by several degrees Celsius and several grams per kilogram, respectively, over a distance of just a few kilometers. Because of the steep (adiabatic) lapse rate in the Saharan air, the positive temperature anomaly diminishes rapidly with height and tends to vanish near $650 \mathrm{mb}$, above which the dusty air may be slightly cooler than the normal tropical environment. Associated with this large-scale temperature contrast is a wind maximum of up to $40-50 \mathrm{kt}$ in the Saharan air layer, usually between 600 and $700 \mathrm{mb}$.

The westward speed of the Saharan air mass is usually about $15 \mathrm{kt}$, requiring about 5-6 days to cross the Atlantic. The leading edge of the Saharan air is of ten found immediately to the rear (east) of a large-amplitude African disturbance which also migrates from Africa to the Caribbean during the summer months at about the same forward speed. Normally the strongest winds and highest dust concentrations in the Saharan air are found in the southeasterly winds behind the disturbance and are therefore associated with the socalled "surges in the trades" which are often observed in the tropical Atlantic.

Saharan air pulses tend to leave the continent of Africa with a potential temperature of $43-44 \mathrm{C}$, about 3-4C higher than that found in the Saharan layer over the Caribbean. This apparent cooling is due to net radiation losses within the Saharan air which amount to about $0.7 \mathrm{C}$ per day. At the same time the Saharan air sinks by $50-100 \mathrm{mb}$ (a mean descending motion of $1-2 \mathrm{~mm} \mathrm{sec}-1$ ) between Africa and the Caribbean.

A model is proposed which depicts the movement of Sabaran air from Africa to the Caribbean and its interaction with African disturbances. Although it is not known what effect, if any, the dust plume has upon the growth or suppression of disturbances, it is clear that the warmth of the Saharan air has a strong suppressive influence on cumulus convection and that, as a result, the advancing dust pulse is often marked by rapid clearing behind the disturbances.
\end{abstract}

\section{Introduction}

Recent work by Prospero and Carlson (1970) and Prospero et al. (1970) has documented the westward movement of masses of dusty air from North Africa to the Caribbean, specifically to the region of Barbados, West Indies (13N, 59W). Aerosol studies carried out at

${ }^{1}$ Contribution No. 1455 from the University of Miami Rosenstiel School of Marine and Atmospheric Science. 


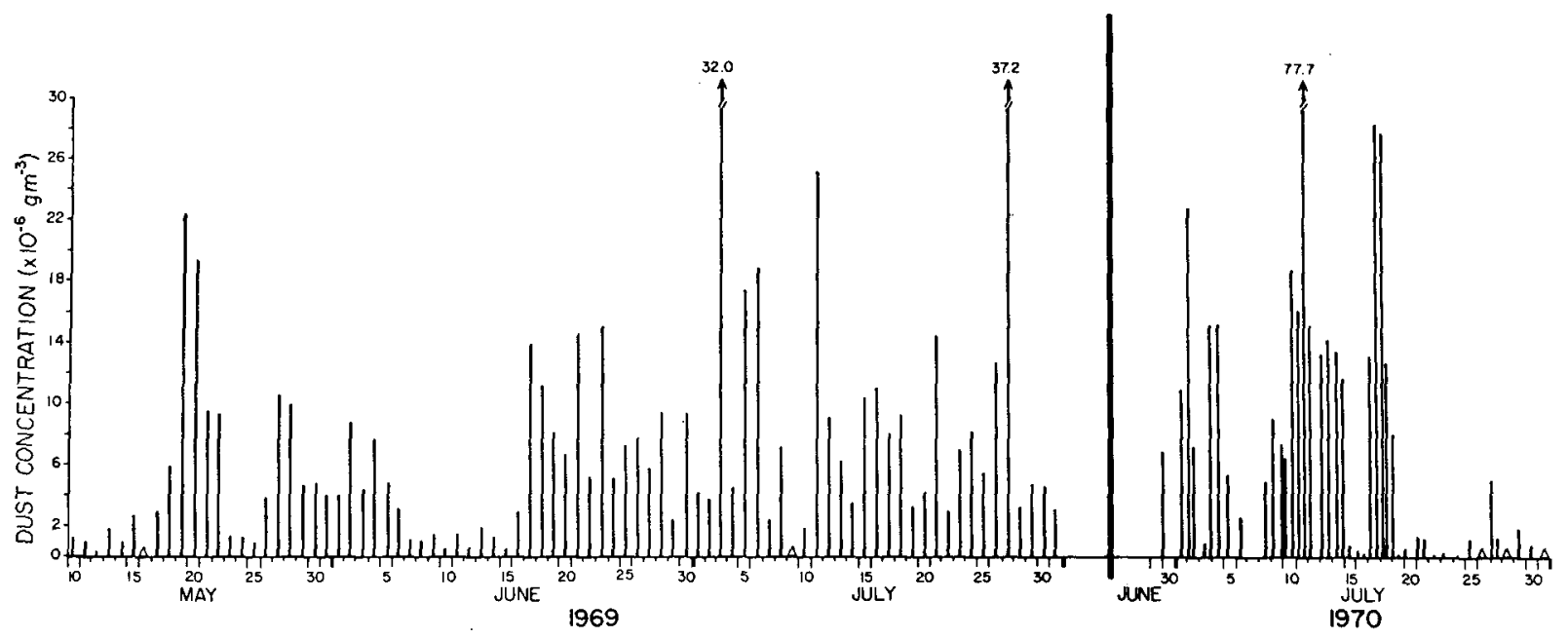

FIG. 1. Atmospheric dust concentration, Barbados, West Indies, May-July 1969 and July 1970. The dust concentration in surface air was measured using the mesh technique described by Prospero (1968). The aerosol collectors used in this study have a low collection efficiency for particles below several microns radius; calculations based on independent measurements at Barbados of aerosol size distributions in the range of $0.3-5 \mu$ radius (Blifford, 1970) indicate that the actual dust load is about three to six times greater than the values presented here. Sampling was carried out continuously (i.e., $24 \mathrm{hr}$ a day) during the periods shown. The individual data points for the 1969 period represent the average dust load $\left(\mu \mathrm{g} \mathrm{m}^{-3}\right)$ for a 24 -hr period as measured from 1800 (all times local standard, LST) the preceeding day; for example, the data point for 20 May 1969 indicates that the average dust load for the period 1800 LST 19 May to $1800 \mathrm{LST} 20 \mathrm{May}$ was $19.4 \mu \mathrm{g}$ per cubic meter of air. During 1970 , the sampling time on some days was divided into two periods: from 1800 to 0800 the following day and from 0800 to 1800 ; for example, the data bar plotted for 11 July indicates that the average dust load from 1800 LST 10 July to 0800 LST 11 July was $16.2 \mu \mathrm{g} \mathrm{m}^{-3}$ while the dust load from 0800 to 1800 LST 11 July was 77.7 $\mu \mathrm{g} \mathrm{m}^{-3}$. Open triangles indicate that no sample was taken.

Barbados between 1965 and 1969 show that the amount of airborne dust reaching the island is highly variable from day to day, especially during the summer months when the atmospheric dust concentration is greatest (see Fig. 1). The average daily dust load during this four-year period was $\sim 2 \mu \mathrm{g} \mathrm{m}^{-3}$, although amounts in excess of $20 \mu \mathrm{g} \mathrm{m}^{-3}$ are not uncommon (Prospero, 1968; Prospero et al., 1970). In contrast, during the winter the dust content of the atmosphere at Barbados is smaller by one or two orders of magnitude; the dust is also grey or black as compared to the light red-brown color of the summer dust. The onset of the maximum dust transport period is often rather abrupt (Prospero, 1968) and corresponds to the inception of airflow from the western Sahara. From August until October or November the average dustiness at Barbados is fairly high but exceptionally dusty periods become less frequent and less intense, and there are extended periods when the air is essentially dust free. The probable origin of the redbrown dust transported during summer and early fall appears to be the area encompassing southern Algeria, Mali, Mauritania, Spanish Sahara and Senegal (Prospero et al., 1970). From December through May, the source region of the black dust is primarily the semiarid grasslands south of the Sahara (Delany et al., 1967).

Although we have been able to relate several periods of unusually high dust concentrations at Barbados to specific outbreaks of dust-storm activity over the Sahara (Prospero et al., 1970), conventional surface observations of dust-storm activity or haze over West Africa and the eastern Atlantic are not good predictors for the eventual arrival of African air (and dust) at Barbados. Instead, we have found that the presence of African air over the equatorial Atlantic is related to large-scale processes occurring over Africa and is readily detected on meteorological soundings as a layer of relatively warm air between 600 and $800 \mathrm{mb}$. The air within this layer has an almost constant potential temperature and slowly changing mixing ratio with height. Evidence which we gathered during BOMEX and on later field expeditions further shows that the variation in the dust content of the air at Barbados is related to the passage of tropical disturbances (easterly waves) and that the trajectories of the dusty air parcels between Africa and the Caribbean are influenced by these travelling systems, called "African" disturbances by Carlson (1969a, b) because of their sub-Saharan origin.

It is our purpose in this paper to describe the African dust layer and its movement across the Atlantic into the Caribbean. To accomplish this, we will utilize conventional meteorological observations combined with a number of specialized measurements made by us during BOMEX in 1969 and on the oceanographic vessel, the U.S.C.G. Discoverer, during the summer of 1970 as well as on the island of Barbados and at Miami.

\section{Background}

The appearance over the Atlantic of African air parcels having uniquely identifiable characteristics can be more readily understood by considering the early 
history of the airstream over Africa. As air proceeds across the arid portions of the continent, it is intensely heated at the earth's surface because of the strong solar radiation, a disproportionately large fraction of which is redistributed to the lower atmosphere in the form of sensible (rather than latent) heat. This heating produces vigorous dry convection throughout a layer of air in convective contact with the ground. Because of the vastness of the desert terrain and the intensity of the heating, a column of air entering the Sahara remains in convective contact with the ground for a period of at least a few days and acquires a uniform potential temperature in the mixing layer, typically about $45 \mathrm{C}$ in July; this layer can extend to $500 \mathrm{mb}$ in the warmest season (Carlson and Ludlam, 1965). As the layer of dry convection deepens, the rate of radiative heat loss gradually increases, eventually approaching the rate at which energy is gained by heating; consequently, the rate of warming becomes progressively smaller. The soundings in Fig. 2 show that in travelling from Tobruk, which lies on the coast upwind from the desert, to Tamanrasset in the interior, the air acquires a considerable amount of sensible heat but little moisture. At Tamanrasset the potential temperature is almost constant at $317 \mathrm{~K}$ (44C) up to $450 \mathrm{mb}$ where it is capped by a stable layer. Similarly, the mixing ratio changes slowly up to $550 \mathrm{mb}$, above which the air is saturated. The Saharan air is therefore especially warm and dry in the lower part. However, the air is cooler than the surrounding tropical air mass near the top where the rising thermals, because of vigorous mixing, overshoot the equilibrium level and incorporate air from above into the mixing layer. This results in the further deepening of the mixing layer and the formation of an inversion at its top. The relative humidity in the layer of dry mixing increases very rapidly with height and may achieve saturation near the top, as in the case for Tamanrasset (Fig. 2); however, saturation usually does not occur unless the layer is lifted subsequent to mixing. (Tamanrasset lies on a high mountain ridge and the air arriving there is subject to some lifting.)

\section{Structure of the dust layer as revealed by air- borne measurements}

Radon-222 measurements made from aboard aircraft during BOMEX have been very useful in the study of Saharan air transport. Randon-222 is a radioactive (half-life 3.82 days) inert gas which is produced by the uranium-238 decay series. [In our work, we determined the air concentration of radon by filtering out and immediately measuring the activity of the short-lived daughter products of radon, principally $\mathrm{Pb}-214$ and $\mathrm{Bi}-214$. The procedures are discussed in Prospero and Carlson (1970).] As is the case with sensible heat and water vapor, radon is introduced into the atmosphere at the earth's surface (Servant, 1966); since radon has about the same vertical eddy diffusivity as that of heat

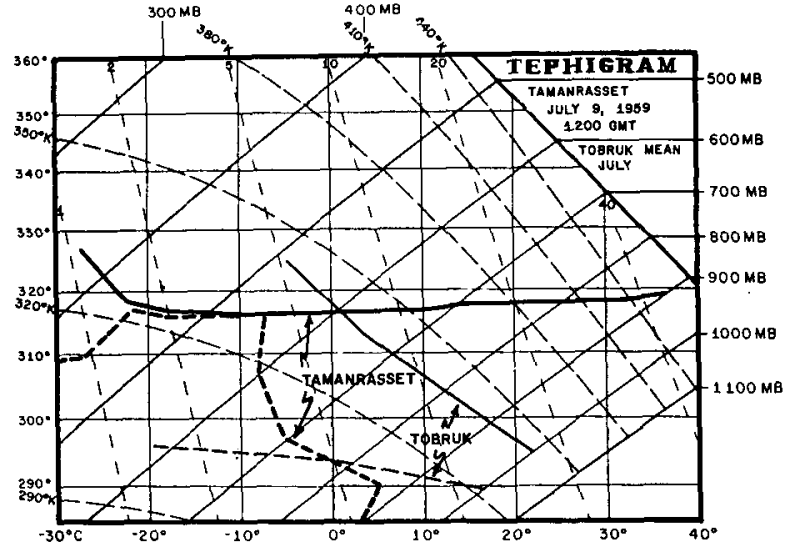

FIG. 2. Soundings for Tamanrasset (southern Algeria) at 1200 GMT 9. July 1959 and Tobruk, Lybia [(July mean), after Carlson (1965) ]. Henceforth, the solid lines refer to the temperature and the dashed lines to the dewpoint (mixing ratio). Horizontal scale lines labelled in degrees Kelvin are the dry adiabats (isentropic surfaces).

or water vapor (Pearson and Jones, 1966), the gas should achieve a similar vertical distribution throughout the mixing layer. However, the emanation rate of radon from the ocean is about 100 times less than that over land (Servant); consequently, oceanic air parcels which have not been in recent convective contact with a continental land surface (i.e., within several radon-222 half-lives, or roughly ten or more days) will have a relatively low radon concentration. The general validity of this reasoning is supported by radon-222 measurements made during a trans-Atlantic flight from Barbados to Africa and return (Prospero and Carlson, 1970); the radon concentration within areas of dense dust-produced haze was markedly higher than in clear areas or above the upper inversion.

\section{a. Case 1: 14 July 1969}

The mesoscale structure of the African dust layer over the western tropical Atlantic can be illustrated using data gathered by us during BOMEX. On 14 July 1969, a weak African disturbance arrived over the BOMEX area and produced a dramatic increase in cloudiness, a common occurrence when easterly waves arrive at the eastern side of the semi-permanent upper cold trough in this area (Frank, 1969). On the 13th, considerable cloudiness formed just east of the wave axis (as defined by the wind shift line on streamline charts), which in Fig. 3 is shown near 56W. A number of research aircraft operated by the Research Flight Facility (RFF) of the National Oceanic and Atmospheric Administration (NOAA) investigated the disturbance. The main cloud area (labelled "dense cloud, showers" in Fig. 3) consisted of altocumulus and altostratus having a base slightly above the upper flight level $(10,000 \mathrm{ft})$; within this cloud area were embedded rising cumulus towers whose tops were less than $25,000 \mathrm{ft}$ (as viewed on the range-height radar of the $\mathrm{DC}-6$ ), except for one cell 


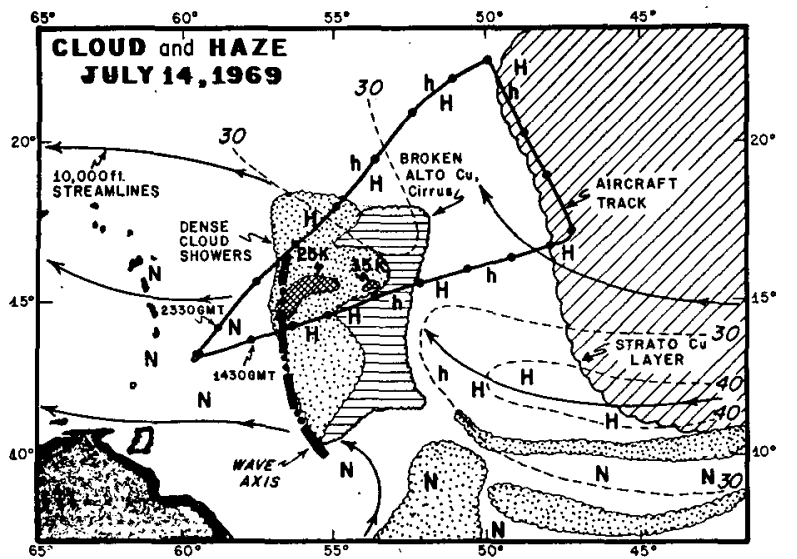

FIG. 3. Weather and haze distribution for approximately 1600 GMT 14 July 1969. The triangular DC-6 aircraft track is divided into half-hour segments by the filled circles, the first and last halfhour intervals beginning at 1400 and 2330 GM'T, respectively. The letters $H$ and $h$ refer to visual haze observations made by aircraft at 10,000 and $1300 \mathrm{ft}$, respectively. The letter $\mathrm{N}$ signifies that no haze was reported by aircraft. The $10,000 \mathrm{ft}$ streamlines (solid barbed lines) and isotachs (thin dashed lines labelled in knots for speeds of 30 and $40 \mathrm{kt}$ ) are shown in the figure. Major cloud areas are enclosed by the various stippling and hatching and are labelled accordingly. The two cross-hatched areas located inside the main cloud band near the disturbance axis contain the majority of radar echoes observed by the DC- 6 aircraft. Representative echo tops are indicated by the labels $25 \mathrm{~K}(25,000 \mathrm{ft})$ and $35 \mathrm{~K}(35,000 \mathrm{ft})$.

(near the flight track at 1530 GMT near $54 \mathrm{~W}$ ) which reached $35,000 \mathrm{ft}$. To the east of this cloud mass was a thin broken layer of altocumulus topped by some cirrus and, beyond that a virtually clear zone. After 1730 GMT the aircraft encountered a shallow layer of stratocumulus along the eastern edge of the track from which it emerged near 1930.

Radon concentrations (measured aboard the DC-6 RFF aircraft, 40C) are listed on Fig. 4 along the outside of the track in units of picocuries per standard cubic meter of air $\left(\mathrm{pCi} \mathrm{m}^{-3}\right.$; a picocurie is $10^{-12}$ curies or 2.2 disintegrations per minute).

The color density of the filters used for the radon measurements provides a rough indication of the atmospheric dust concentration. We established a logarithmic color scale on the basis of the variations of color density observed between successive filters having a three-fold difference in sampling duration. (Series of samples in which sampling times alternated between 5 and $15 \mathrm{~min}$ were frequently taken whenever the aircraft maintained constant altitude for extended periods.) The color sorting of the approximately 1400 filters obtained during $300 \mathrm{hr}$ of in-flight sampling during BOMEX yielded a graded color scale of 10 ; this scale was placed on a semiquantitative basis by correlating the color density of a similar series of filter samples taken on Barbados with the dust loads measured there using the previously described mesh technique (Prospero, 1968). The scale of 10 represents a dust concentration variation which ranges from less than $1 \mu \mathrm{g} \mathrm{m}^{-3}$ to approximately $50-100$ $\mu \mathrm{g} \mathrm{m}^{-3}$. The dust loading estimates derived from the filter color index for the flight of 14 July are shown along the inside of the track.

Ahead of the wave axis, the radon concentrations were about $3-4 \mathrm{pCi} \mathrm{m}^{-3}$; these values are typical oceanic background levels and are consistent with the interpretation that the air parcel had not recently been in convective contact with a continental land surface. In addition, the filter color index was low. This situation persisted until the wave axis had been passed and the plane began to level off near 10,000 ft after an ascent from $1300 \mathrm{ft}$. At that point the radon began to increase rapidly toward the east, reaching $41 \mathrm{pCi} \mathrm{m}^{-3}$ in the cloud-free zone near $49 \mathrm{~W}$. The filter color index increased in the same manner, showing the dustiest air to be slightly east of the highest radon concentrations and near the position of a warm temperature ridge. The onset of these higher values of radon and dust load (i.e., filter index) was accompanied by a marked increase in temperature in which the potential temperature rose by $3.5 \mathrm{C}$ over the course of $\sim 100 \mathrm{mi}$, as indicated in Fig. 4. In this particular example, the light showers intermittently falling from the middle cloud deck (the stippled area of Fig. 3) may have led to an exaggeration of this temperature contrast by producing evaporative cooling of the air beneath the cloud layer and to anomalous (wet bulb) cooling of the vortex temperature sensor; nonetheless, the large-scale temperature gradient is quite real. This warming is evident upon inspection of Fig. 5 in comparing the temperatures at points $\mathrm{B}$ or $\mathrm{C}$ which lie within the hazy air with those at point $A$ or on the Barbados sounding which represent observations made outside the hazy regime.

Fig. 3 shows that haze was prevalent east of the wave axis and north of the zone of cloudiness located between

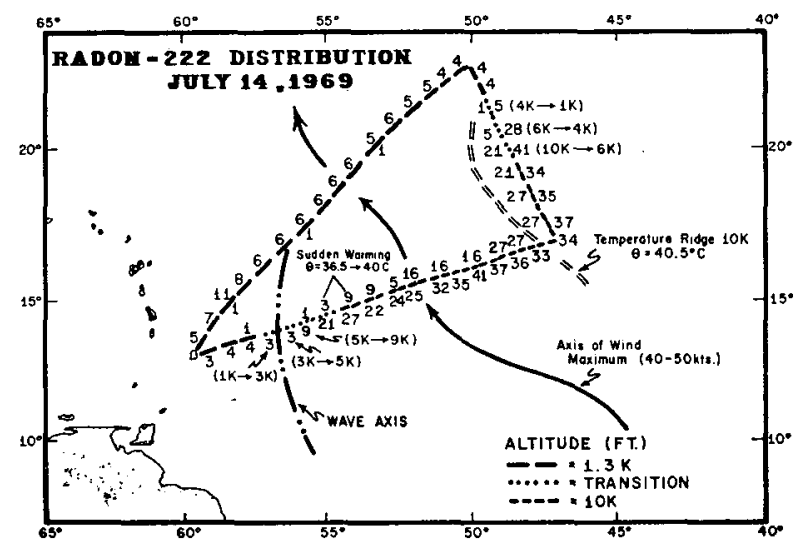

FIG. 4. Radon-222 concentrations measured along the DC-6 aircraft track shown in Fig. 3. The figures to the right (outside) of the track are the radon concentrations in picocuries per cubic meter and the numbers on the left (inside) of the track are the filter color index values which are roughly equivalent to the dust load expressed in micrograms per cubic meter of air. The duration of individual measurements ranged from 5 to $15 \mathrm{~min}(15$ to $50 \mathrm{mi})$. Changes in aircraft altitude from the 1300 - or 10,000 -ft levels are indicated by the dotted lines and labelled accordingly. 
5 and $10 \mathrm{~N}$ which we can identify with the Intertropical Convergence Zone (ITC). However, no haze was observed by aircraft west of the disturbance. Haze was also visible at $1300 \mathrm{ft}$ east of the disturbance (Fig. 4), but was considerably thinner than that reported at $10,000 \mathrm{ft}$. The layered character of the air in this region is revealed most strikingly by the extremely rapid decrease in the values of radon concentration and filter color density during the rapid descent of the aircraft from 10,000 to $1300 \mathrm{ft}$ near $20 \mathrm{~N}, 49 \mathrm{~W}$. The rapid increase in potential temperature (and decrease in mixing ratio) that occurred near $55 \mathrm{~W}$ at about 1500 GMT and the subsequent gradual increase to a value of $40.5 \mathrm{C}$ at the temperature ridge (see the respective segments $A B$ and $B C$ in Fig. 5) coincided with increases in radon concentration and filter index. An isentropic layer is visible on the sounding in Fig. 5 from $\mathrm{C}$ to $\mathrm{D}$, representing the lower portion of the Saharan mixing layer penetrated by the aircraft as it descended from $\mathrm{C}$ to $\mathrm{E}$ and thence into the stratocumulus layer. The low radon concentrations and low dust loads (i.e., low filter color index) measured during the latter part of the flight clearly indicate that the air was of nonSaharan origin.

The full depth of the Saharan air layer is shown on the sounding made at the Discoverer on the following day under hazy and suppressed conditions (Fig. 6). Saharan air, evidenced by the steep lapse rate of temperature and increasing relative humidity with height, is recognizable between 820 and $580 \mathrm{mb}$. Although the lapse rate is somewhat more stable than the dry adiabatic in the Saharan layer, the sounding is similar to the temperature profile obtained at Sal, Cape Verde Islands, shortly after the same wave disturbance had passed that island

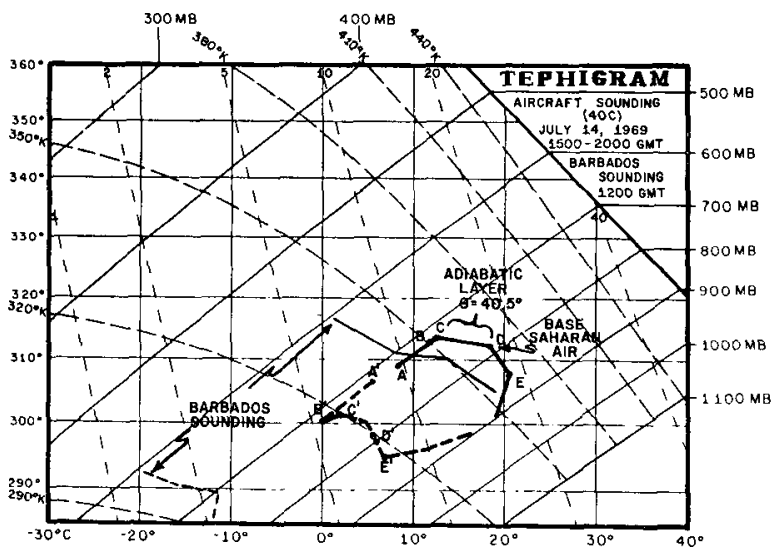

FIG. 5. Temperature and dewpoint soundings on 14 July 1969, as made by aircraft (heavy solid and dashed lines) and by the Barbados radiosonde (thin solid and dashed lines). The segments $\mathrm{ABC}$ (temperature) and $\mathrm{A}^{\prime} \mathrm{B}^{\prime} \mathrm{C}^{\prime}$ (dewpoint or mixing ratio) were recorded when the plane flew horizontally between 1500 and 1900 GMT. The most rapid warming was between A and B (see text) during the first half hour. The segments CDE and $\mathrm{C}^{\prime} \mathrm{D}^{\prime} \mathrm{E}^{\prime}$ were recorded during descent at approximately 1930-2000 GMT. Saharan air is indicated between 720 and $790 \mathrm{mb}$ on the aircraft sounding. The Barbados sounding was made west of the wave axis, while the aircraft record was obtained east of the wave axis.

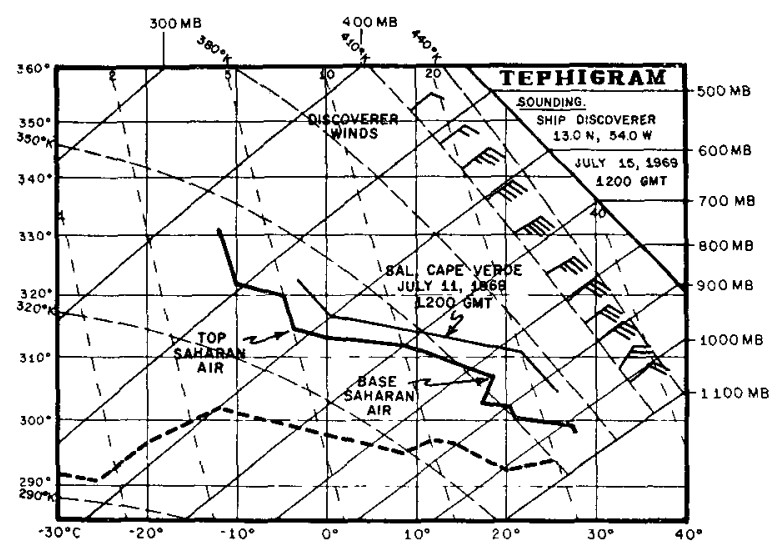

FIG. 6. Temperature and dewpoint sounding from the Discoverer and the temperature sounding for Sal, Cape Verde Islands. The vertical wind profile for the Discoverer (beaufort scale) is shown at the right. Saharan air is located on both soundings approximately between 820 and $600 \mathrm{mb}$. There is a wind maximum of 46 kt near $670 \mathrm{mb}$ at the Discoverer.

some three days prior to entering the BOMEX area. In contrast, the Barbados sounding made ahead of the wave axis at 1200 GMT 14 July (Fig. 5) fails to exhibit any deep isentropic layer and may be devoid of Saharan air except for a possible thin, cool segment located between 700 and $760 \mathrm{mb}$. Moreover, the relative dryness at Barbados precludes the explanation that Saharan air had passed through the disturbance; if this had occurred, the air parcel would have had a much higher mixing ratio because of the effects of cumulus convection and rainfall.

At Barbados, the dust concentration at the surface increased by a factor of 3 [from 3.5 to $10.5 \mu \mathrm{g} \mathrm{m}^{-3}$ (see Fig. 1)] following the passage of the wave disturbance. However, the increase was not as dramatic as that observed on the flight at $700 \mathrm{mb}$ where, on the basis of the filter index, the dust load increased by a factor of about 27.

Exceptionally strong winds having a jet maximum of $\sim 45 \mathrm{kt}$ near $650 \mathrm{mb}$ were observed within the Saharan air layer; these winds are evident in the Discover sounding shown in Fig. 6. High winds were confined to the east of the disturbance where speeds in excess of $40 \mathrm{kt}$ were reported by Navy aircraft at the $10,000-\mathrm{ft}$ level (Fig. 3). Following the passage of the disturbance, the wind speeds at upper levels over the Antilles increased markedly, and the vertical wind profiles there came to resemble the one shown in Fig. 6. It seems quite likely, therefore, that the marked temperature contrast between the warm Saharan air and the relatively cooler tropical surroundings is somehow responsible for the strong winds inasmuch as the geostrophic thermal wind equation would imply strong vertical wind shear in the vicinity of the large-scale temperature contrast. Because of the extraordinary sharpness of the discontinuity, however, a particular point located within the zone of "sudden warming" shown in Fig. 4 may 


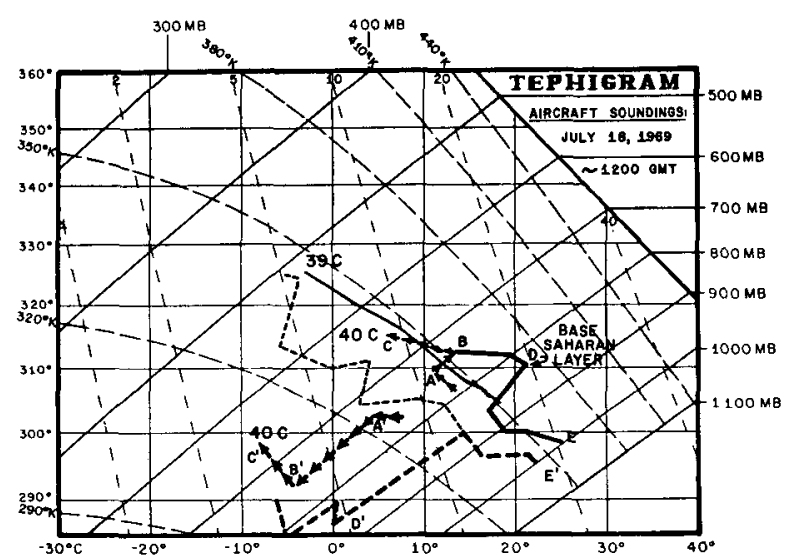

FIG. 7. Aircraft temperature and dewpoint soundings made by the 39C DC-6 (thin lines) on continuous ascent east of Barbados, W.I. and by the $40 \mathrm{C}$ aircraft (heavy lines) ascending to point $\mathrm{AA}^{\prime}$, flying horizontally through the dust front to $\mathrm{BB}^{\prime}$, ascending behind the dust front to $\mathrm{CC}^{\prime}$, and later descending to $\mathrm{DD}^{\prime}$ and $\mathrm{EE}^{\prime}$. Saharan air is recognizable between 670 and $820 \mathrm{mb}$ on the $40 \mathrm{C}$ sounding.

not be experiencing even approximate geostrophic equilibrium.

It is important to note here that the anomalous warmth of the Saharan layer is greatest at the base of the isentropic segment and may vanish above about $650 \mathrm{mb}$, where the layer becomes a little cooler than normal. As will be shown in subsequent examples, the wind speed also tends to diminish very rapidly with height above the $600-700 \mathrm{mb}$ wind maximum.

\section{b. Case 2: 18 July 1969}

In another episode during BOMEX, an aircraft flew into a large mass of hazy air to the rear of an African disturbance on 18 July 1969. The pair of soundings in Fig. 7 and the profiles of temperature, mixing ratio, wind velocity, radon concentration, and filter color index in Fig. 8 illustrate the exceedingly sharp definition of the interface between the Saharan air stream and its surroundings. In order to emphasize the steepness of this transition, we will hereafter refer to the leading edge of the Saharan dust plume as the "dust front" and the small-scale temperature-dewpoint contrast between air masses as the "Saharan air front"; the use of the term "front" is not meant to suggest a mid-latitude type of feature, however.

The RFF DC-6 aircraft, 39C, ascended to $520 \mathrm{mb}$ in the vicinity of $14 \mathrm{~N}, 58 \mathrm{~W}$ and proceeded eastward at this level. Throughout the ascent and thereafter, the radon concentrations remained relatively low (10-15 $\mathrm{pCi} \mathrm{m}^{-3}$ ) and the filters were essentially clean. The temperature sounding produced during the ascent phase of this flight, shown in Fig. 7, is very close to that of the mean tropical sounding for July, although the humidity at middle levels was somewhat higher than the average indicating that the air may have interacted recently with cumulus convection. A cloud mass associ- ated with a travelling disburbance of African origin was located near the Lesser Antilles but the weather over Barbados and further east was undisturbed except for numerous trade wind cumuli and an occasional towering cumulus.

Another DC-6 aircraft, the RFF 40C, flying below the $39 \mathrm{C}$ aircraft, proceeded eastward at $720 \mathrm{mb}$ and encountered the dust front near $56 \mathrm{~W}$ (Fig. 8); within a few minutes (over a distance of $\sim 20 \mathrm{mi}$ ) the potential temperature rose by $4 \mathrm{C}$ from 36 to $40 \mathrm{C}$ and the mixing ratio decreased by over $7 \mathrm{gm} \mathrm{kg}^{-1}$ to $3.6 \mathrm{gm} \mathrm{kg}^{-1}$, values which were maintained for at least several hundred miles inside the dusty air. In crossing the dust front, the radon concentrations rose by a factor of 3 to 30 $\mathrm{pCi} \mathrm{m} \mathrm{m}^{-3}$ and the filter color index increased full scale to 81 (Fig. 8), a value attained on only a few occasions during BOMEX. During this time, the cloud cover became suppressed and the haze grew quite dense. In Fig. 7 the temperature and dewpoint contrast experienced by the aircraft $40 \mathrm{C}$ in crossing the Saharan air front is indicated on the sounding by the segments $A B$ and $A^{\prime} B^{\prime}$, respectively. (The arrows indicate the chronological sequence of events from the aircraft's initial ascent to $720 \mathrm{mb}$ and later to its maximum altitude at $670 \mathrm{mb}$.)

Aircraft 39C, flying at $520 \mathrm{mb}$, visually fixed the location of the Saharan air front at $56 \mathrm{~W}$ but reported that the haze top was well below the flight level. Accordingly, there was no indication of Saharan air either in the radon concentrations or in the filter color index on this flight. Aircraft 40C, however, encountered a portion of the isentropic (and constant mixing ratio) layer between 720 and $670 \mathrm{mb}$ [represented by the segments $\mathrm{BC}$ (temperature) and $\mathrm{B}^{\prime} \mathrm{C}^{\prime}$ (mixing ratio) in Fig. 7]. Later, the aircraft descended to $820 \mathrm{mb}$ near $51 \mathrm{~W}$ and in so doing was able to measure the lower portion of the Saharan mixing layer given by the segments $\mathrm{BD}$ and $\mathrm{B}^{\prime} \mathrm{D}^{\prime}$ in Fig. 7. The aircraft continued to descend to $985 \mathrm{mb}$, obtaining the temperature and dewpoint profiles $\mathrm{DE}$ and $\mathrm{D}^{\prime} \mathrm{E}^{\prime}$, respectively. The sounding from aircraft $40 \mathrm{C}$ shows the presence of a deep layer

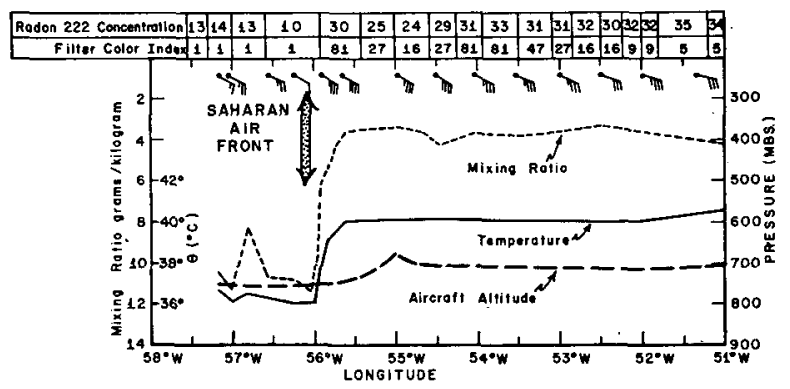

FIG. 8. Temperature, mixing ratio, wind velocity and aircraft altitude measured by the $40 \mathrm{C}$ DC-6 aircraft on an eastward traverse, from 1100-1400 GMT 18 July 1969, through the Saharan air front at approximately $14 \mathrm{~N}$. 'The radon concentration (in picocuries per cubic meter) and the filter color index are listed at the top for the appropriate measurement intervals. 
of Saharan air having an almost constant potential temperature $(\sim 40 \mathrm{C})$ and mixing ratio $\left(\sim 3.6 \mathrm{gm} \mathrm{kg}^{-1}\right)$, respectively, as shown by the segments $C D$ and $C^{\prime} D^{\prime}$ in Fig. 7. Except for a temporary reduction in filter color index and radon concentrations near $55 \mathrm{~W}$, the Saharan-air indicators remained uniformly high until about 53W, after which the filter color index decreased steadily to a value of 5 at the easternmost end of the flight track (Fig. 8). After $51 \mathrm{~W}$ the plane followed a straight line track southwestward to a point near 9N, 54W. Radon concentrations decreased abruptly near $850 \mathrm{mb}$ during the descent but continued to be relatively high $\left(20-24 \mathrm{pCi} \mathrm{m}^{-3}\right)$ until the aircraft reached $10 \mathrm{~N}$. The filter color index increased gradually from 5 to about 27 as the aircraft proceeded southwestward; at $10 \mathrm{~N}$ the dense haze vanished and the radon concentrations and filter color index decreased to low values comparable to those recorded at the beginning of the flight, indicating that the aircraft had emerged from the southern edge of the Saharan dust plume. It should be noted also that no haze had been reported in the ITC south of about $10 \mathrm{~N}$ on 14 July (see Fig. 3). (However, on 23 July, a case not discussed in this paper, Saharan air was observed well within the region of ITC cloudiness between 5 and 10N.)

Wind velocities also changed abruptly at the dust front (see Fig. 8), increasing in speed to about $40 \mathrm{kt}$ and backing slightly to southeasterly within the plume. The winds reached a maximum near the dust front and thereafter gradually decreased further toward the east. In contrast, during the 14 July case the highest speeds occurred a few hundred miles behind the Saharan air front.

\section{Large scale movement of the Saharan dust plume \\ a. Over the eastern Atlantic}

During the morning of 30 July 1970, while cruising near the Cape Verde Islands, the Discoverer suddenly

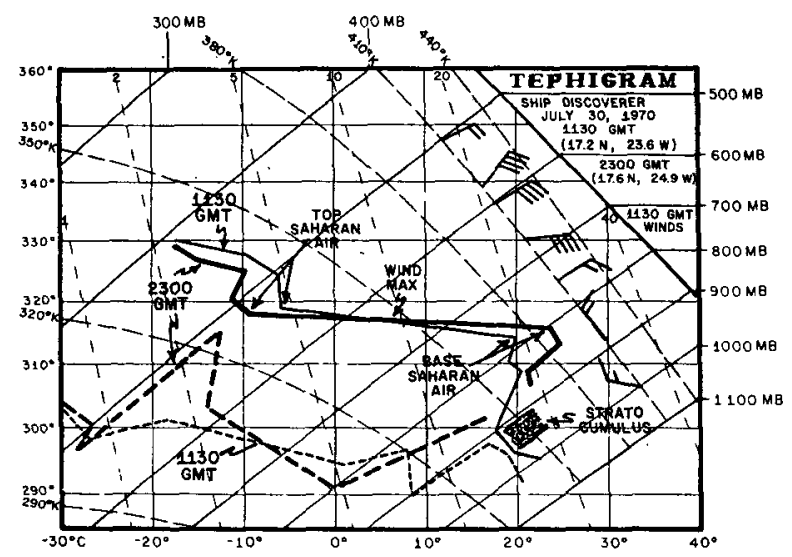

FIg. 9. Soundings (1130 and 2300 GMT, 30 July 1970) made from the Discoverer near the Cape Verde Islands. The wind profile for the earlier sounding is listed at the right showing the presence of a wind speed maximum between 600 and $700 \mathrm{mb}$. A shallow layer of stratocumulus is indicated below $900 \mathrm{mb}$.

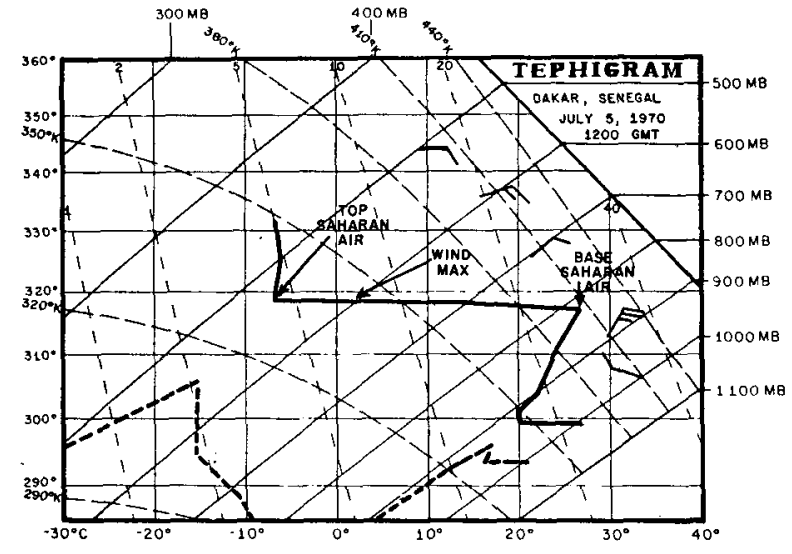

FIG. 10. Sounding and wind profile for Dakar, Senegal (1200 GMT 5 July 1970), showing a layer of Saharan air between 540 and $820 \mathrm{mb}$ with an almost uniform lapse rate of temperature and mixing ratio. Note in the wind profile the counterflow of maritime air along the coast below the Saharan air layer.

encountered dense haze after a period of a day or so with little haziness. No Saharan air had been visible on the Discoverer sounding made $12 \mathrm{hr}$ earlier, but the deep isentropic layer evidently appeared sometime prior to the 1130 GMT sounding where it is clearly recognizable between 540 and $780 \mathrm{mb}$ (Fig. 9). During the following $12 \mathrm{hr}$ the isentropic layer deepened by about $50 \mathrm{mb}$, the base remaining just above a very thin layer of stratocumulus. A wind speed of $40 \mathrm{kt}$ is also visible between 600 and $700 \mathrm{mb}$. The temperature and dewpoint stratification visible in the soundings in Fig. 9 is commonly observed off the coast of Africa at this time of year. The lower (cooler and moister) portion of the sounding is attributable to the northerly maritime flow along the coast. These winds have a persistent landward component on the western coast of North Africa. Consequently, the Saharan air is undercut by the cool maritime current well inland from the coast as is evident from the Dakar sounding in Fig. 10.

The arrival of this dusty air aloft is reflected in the deck-level measurements of radon concentration, atmospheric dust loading, and turbidity, all of which show an increase from the 29th to the 31st; except for radon, uniformly high values were maintained until the ship entered port three days later on 3 August (Fig. 11). The turbidity $B$, measured with a Volz photometer at $0.5 \mu$ wavelength (Flowers et al., 1969; Volz, 1970), rose to 0.28 on 31 July; this value is comparable to that measured in urban regions under conditions of dense haze usually attributable to human activity (Flowers et al., 1969; Volz, 1969).

The onset of haziness at the Discoverer occurred one or two days after a large-amplitude African disturbance passed the vessel; the passage of the disturbance seemed to be associated with a narrow arc-like band of stratocumulus which on satellite photographs appeared to be radiating from the African coast and which was first recognized shortly after the disturbance (shown at 


\begin{tabular}{|c|c|c|c|c|c|}
\hline OBS & CLOUDY & $\begin{array}{l}\text { VERY } \\
\text { HAZY }\end{array}$ & OUSTY & HAZY & HAZY \\
\hline $\begin{array}{l}\text { DUST } \\
\text { LOAD }\end{array}$ & & VA & 0 & 8 & 77 \\
\hline B & & & & & \\
\hline $\begin{array}{r}15 \\
R n \\
10 \\
5\end{array}$ & & & & & \\
\hline
\end{tabular}

FIG. 11. Dust and African air-indicator measurements from the Discoverer, 29 July-2 August 1970 , showing dust load $\left(\mu \mathrm{g} \mathrm{m}^{-3}\right), B$ (turbidity) and $\mathrm{Rn}\left[\right.$ radon- 222 concentration $\left.\left(\mathrm{pCi} \mathrm{m}^{-3}\right)\right]$. The position of the data bars indicates the time of measurement; the width of the dust load data bar shows sample duration. Radon-222 samples are 30 min long. The vessel entered port on 3 August and measurements were terminated

about $40 \mathrm{~W}$ in Fig. 12) crossed the African coastline $\mathrm{e}^{2}$ late on the 26th. The leading edge of this arc, delineated by the serrated border in Fig. 12, appears to form a discontinuity between the large-sized stratocumulus cells to the west and the smooth, small-celled stratocumulus and clearing weather to the east. ${ }^{3}$ The winds at the ship gave no evidence of the passage of a second, but weak, low-latitude wave which passed south of the ship on the 30th. Instead, the winds strengthened at middle levels and backed gradually to the northeast by 2 August, immediately prior to the passage of the next major disturbance (shown at $12 \mathrm{~W}$ in Fig. 12).

As this next major wave approached the Discoverer, the haze and the associated indicators decreased and, with the exception of radon, ultimately attained low values again on 4 August. In contrast, the radon concentrations increased markedly with the passage of the cloud arc which signaled the arrival of Saharan air aloft on the 30th; the radon then decreased abruptly about the time the skies cleared on 31 July and fluctuated thereafter.

We have frequently observed these somewhat erratic fluctuations in radon concentration in surface and lowlevel air and interpret them as being indicative of the extent of mixing which has taken place between surface air and the air within the Saharan layer above. Normally, the highly suppressed conditions beneath the Saharan air impede the exchange of air between these layers; however, in areas of convective cloudiness this exchange is facilitated and could lead to the observed abrupt and erratic fluctuations. On occasion, evidence of the effects of convection is seen in soundings from coastal stations of West Africa. For example the Dakar sounding data plotted at $15 \mathrm{~N}, 17 \mathrm{~W}$ in Fig. 12 reveal the presence of a Saharan layer, but one which is relatively cool and moist indicating that cumulus convection may

\footnotetext{
2 For a description of how the disturbances are tracked, see Carlson (1969a).

${ }^{3}$ When Saharan air overrides the maritime cloud cover, the latter becomes suppressed and, in some cases, vanishes entirely. Fresh pulses of Saharan air, therefore, may be accompanied by a sufficiently marked discontinuity in the cloud pattern to become visible on satellite photographs. It is this discontinuity which we have identified as the leading edge of the Saharan dust plume and which is delineated by the serrated border in Figs. 12-14.
}

have partially modified the Saharan air at some earlier time.

In general, deck-level radon measurements made off the coast of Africa during the past several years show concentrations that are comparable to the values found for surface air at Barbados and considerably less than those measured aloft within the Saharan air layer over the Caribbean. The same conclusions hold true for our dust measurements. These observations suggest that the Saharan layer is the principal source for radon and for aerosol particles found in the lower layers and that the dust concentration in the lower layers is determined principally by the settling rate of the particles and the degree of mixing between the low level air and air in the Saharan layer. In a sense, the Saharan air layer can be thought of as functioning as a somewhat leaky "duct" transporting dust to the western Atlantic.

In another episode, intense haze was reported over much of the Caribbean and western equatorial Atlantic during the period 9-14 July 1970; the appearance of haze correlated with the arrival of a dust pulse which could be tracked back to the coast of Africa and there

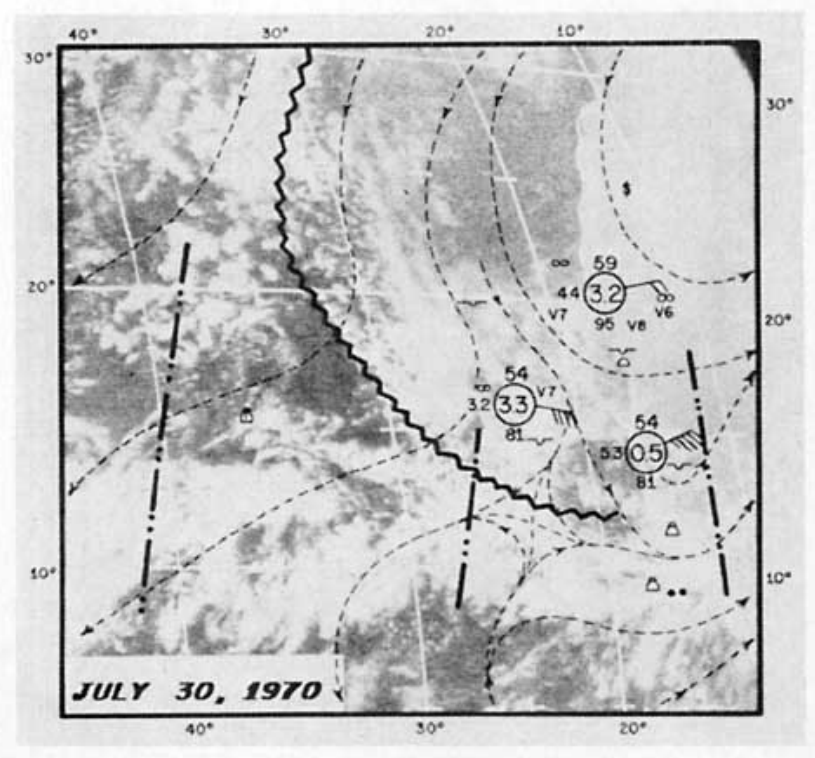

FIG. 12. A'TS-III satellite photograph of the eastern equatorial Atlantic at 1600 GMT 30 July 1970 . Superimposed on the photo are sounding data and surface streamlines for $1200 \mathrm{GMT}$. Each radiosonde station symbol contains a decimal figure which is the $700-m b$ potential temperature in degrees Celsius but with the tens digit deleted (i.e., $39.0 \equiv 9.0$ and $43.2 \equiv 3.2$ ). The numbers at the top and bottom and the decimal number at the left refer, respectively, to the heights of the top and base of the Saharan air in centibars and the average mixing ratio in grams per kilogram. These three values are omitted when Saharan air cannot be found at the station. The wind barbs show direction and speed in the Saharan air at the level of maximum wind speed (or between 850 and $500 \mathrm{mb}$ in the absence of Saharan air). Haze, dust and cloud observations are also included where reported. The horizontal visibility in miles (the number prefixed by the letter $\mathrm{V}$ ) is also listed at surface locations reporting a visibility less than $10 \mathrm{mi}$. The axes of African wave disturbances are indicated by the heavy dash-dotted lines. The serrated border signifies the leading edge of the Saharan air. The data plotted at $17 \mathrm{~N}, 24 \mathrm{~W}$ refer to the 1200 GMT Discoverer sounding of Fig. 9. 

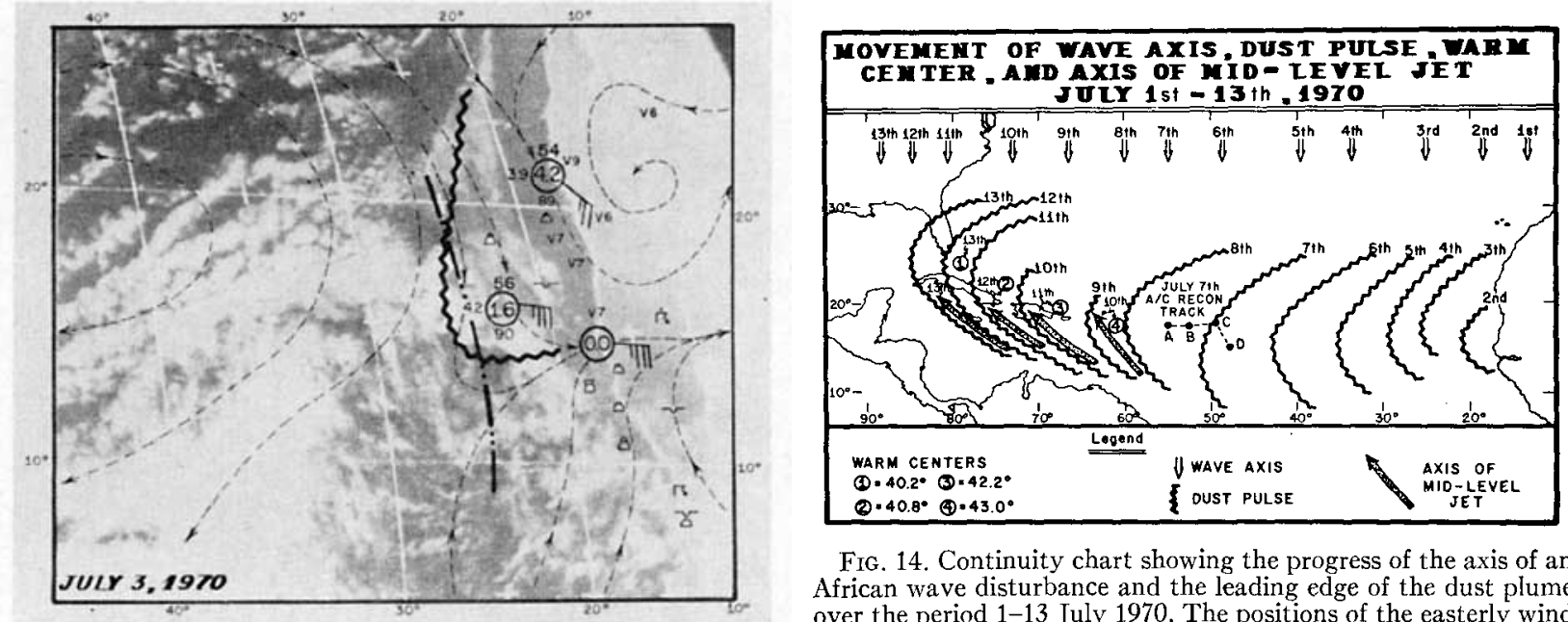

FIG. 14. Continuity chart showing the progress of the axis of an African wave disturbance and the leading edge of the dust plume over the period 1-13 July 1970. The positions of the easterly wind maximum in the Saharan air and the centers of maximum potential temperature are shown for the period 10-14 July. The location of the leading edge of the dust plume during the period

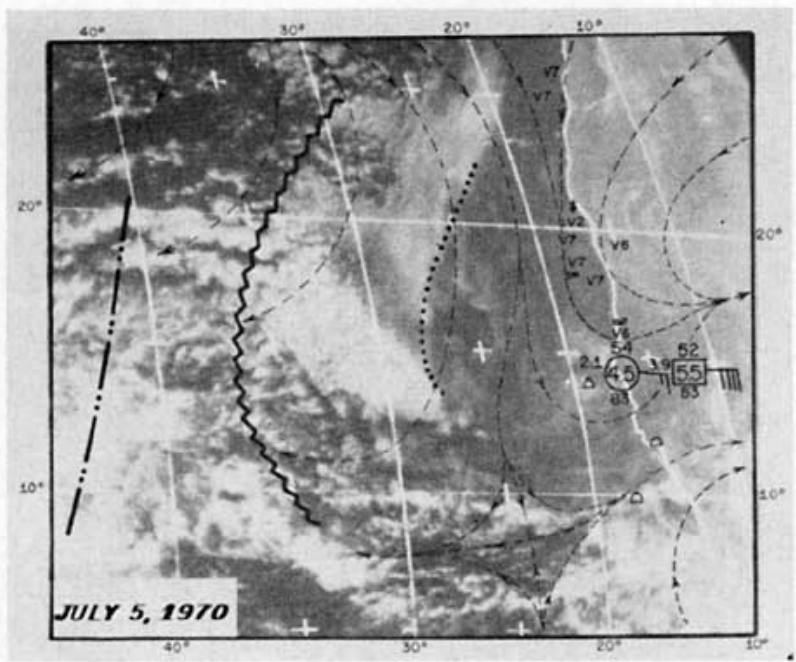
8-13 July was determined on the basis of where Saharan air could be found on the temperature soundings.

associated with a front-like band of stratocumulus similar to the one shown in Fig. 12. Figs. 13 a-c show that this feature moved away from the African coast, following closely behind a large African disturbance which had crossed the coastline on 2 July. The leading edge of this discontinuity first became distinctly visible along the coast of Africa on 3 July, although there was some evidence that it may have emerged late on 2 July.

As in the 30 July example, the highest potential temperatures found in the Saharan isentropic layer on 4 July over the African coast were about $43-44 \mathrm{C}$ and the top of the layer was at a height of about $540 \mathrm{mb}$. By 5-6 July, however, the potential temperature of the Saharan air leaving the continent had increased to $46-47 \mathrm{C}$ and the top had risen slightly to a height of 500-520 mb (Figs. $13 \mathrm{~b}, \mathrm{c}$ ). Soundings along the African coast (such as Dakar or Sal) continued to show Saharan air aloft during this period without any definable interruption in the airstream. Since there was no evidence for the passage of a Saharan air front along the African coast, the leading edge of the Saharan air may have become organized at some distance to the west. ${ }^{4}$ In this case, the earliest direct observation of the Saharan air front was made at $49 \mathrm{~W}$ on 7 July by an Air Force reconnaissance aircraft flying across the band of stratocumulus cloud which had continued to move westward behind the disturbance. Flying at a height of $660 \mathrm{mb}$ along the track $A B C D$ shown in the continuity chart (Fig. 14), the aircraft reported heavy cumulus activity at point $A$ (near the axis of the disturbance) which cleared rapidly at $B$ and was replaced between $B$ and C by small cumulus and some upper layer cloud. At C, clear air turbulance was experienced followed by the

FIG. 13. ATS-III satellite photographs of the equatorial Atlantic for 3 (a), 5 (b) and 6 (c) July 1970. The same display code is used as that in 7 Fig. 12. In $13 \mathrm{~b}$ the serrated edge marks the leading edge of the cloud discontinuity and the dotted line indicates the edge of the clear area, while $13 \mathrm{c}$ shows the larger view of the advancing'cloud discontinuity.

${ }^{4}$ The inability to discern the passage of the Saharan air pulse at Sal may be due to the infrequency with which the sounding from Sal is received. 


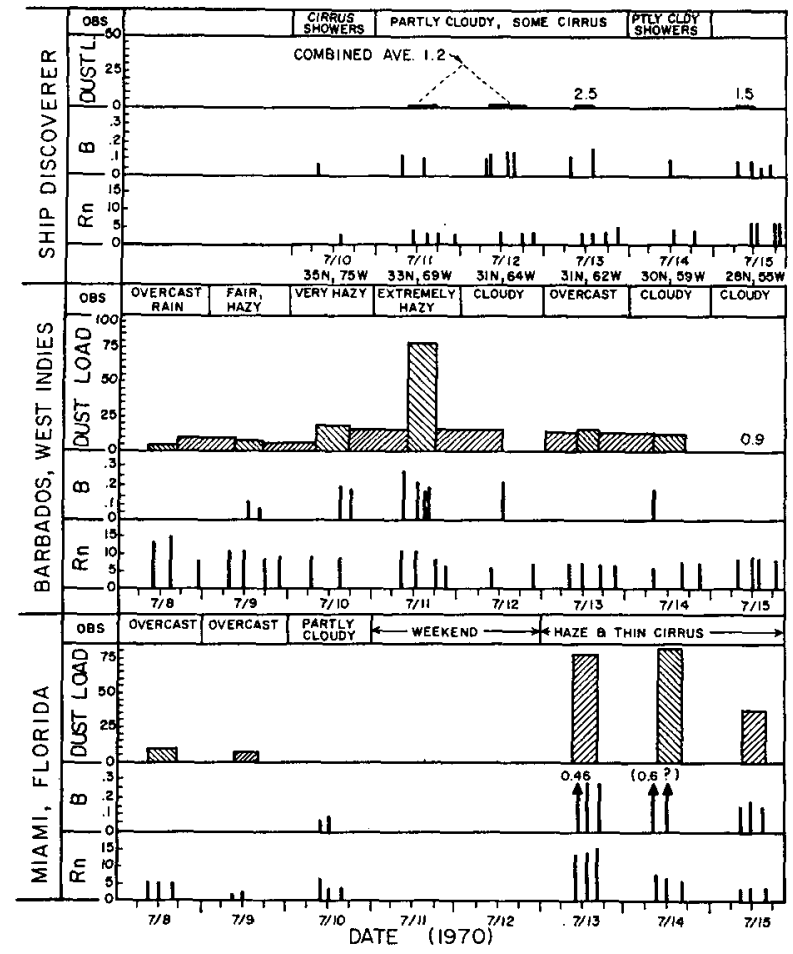

FIG. 15. Dust and African air-indicator measurements: ship Discoverer, Barbados, W. I., and Miami, Fla., 8-15 July 1970 (for coordinates of ship, see figure). Units are the same as in Fig. 11. The dust load data for Discoverer on the 11 th and 12 th are a composited average. The turbidity data for Miami on the 14th are questionable because of the possible effect of thin cirrus which may have been present.

appearance of a haze layer and a $2 \mathrm{C}$ rise in temperature between $\mathrm{C}$ and $\mathrm{D}$; the haze top was reported to be at $640 \mathrm{mb}$ at $\mathrm{D}$.

\section{b. In the Caribbean}

The above-mentioned disturbance passed through the Barbados area late on 8 July and was accompanied by a period of showery weather conditions which ended on 9 July. (The transit time from Africa to Barbados of about 6 days is typical.) The surface air dust loading at that island rose abruptly from virtually zero on the 7 th to $5-9 \mu \mathrm{g} \mathrm{m}^{-3}$ on the 9 th and 10th (Fig. 15) and 15-19 $\mu \mathrm{g} \mathrm{m}^{-3}$ on the 11 th and 12 th with a brief period of exceptionally dusty conditions on the 11th when the dust load rose to $78 \mu \mathrm{g} \mathrm{m}^{-3}$ (see Figs. 11 and 15). Turbidity values also rose accordingly, approaching 0.3 on the 11th. Radon concentrations, however, actually decreased during this period, as would be anticipated by the advent of stable conditions at the base of a deep layer of Saharan air. The presence of a very deep and warm layer of Saharan air over Barbados on the 10th and 11th is evident from the sounding shown in Fig. 16. A characteristic wind maximum is evident near $700 \mathrm{mb}$ on the sounding for that period (Fig. 16).

The analyses in Figs. 17 a-d show the structure and movement of the Saharan air over the Caribbean from 10-13 July. In these Caribbean analyses, the phase speed of the easterly wave, $16 \mathrm{kt}$ westward, is subtracted from the wind vectors in order to depict the air flow relative to the moving dust pulse and wave axis. In contrast to the examples shown for the eastern Atlantic analyses, where the data were not abundant, the western Atlantic analyses enable us to define the exact boundary of the dusty air mass and to chart the trajectory of the air travelling in the core of high winds within the Saharan air layer. Figs. 17 a-d clearly show the following features: 1) the leading edge of the Saharan air, 2) an area of relatively warm and deep Saharan air located some distance to the east of the leading edge of the pulse, and 3) a band of strong winds located between the warm center and the forward boundary of the pulse. (Note that the correction of the winds for relative movement reduces the speed of the absolute easterly wind maxima and increases the strength of the relative westerlies.) The wind barbs suggest an anticyclonic rotation about a center a little to the east of the warm dome. ${ }^{5}$ Surface observations of haze accompanied by low horizontal visibility $(\leqslant 10 \mathrm{mi})$ are infrequent in this region; however, during this 4 -day period, one or two such reports were received daily and each was located near the center of maximum potential temperature (noted in the filled circles in Figs. 17 a-d).

The Discoverer briefly encountered the northern fringe of the dust plume on 12-13 July at about $31 \mathrm{~N}$, $63-64 \mathrm{~W}$, as indicated by the presence of Saharan air aloft on the soundings. Although the turbidity did increase moderately, haze was not reported at the ship. Also, the surface air dust load remained low and the radon concentration failed to rise above the oceanic "background" level (Fig. 15). We can only conclude

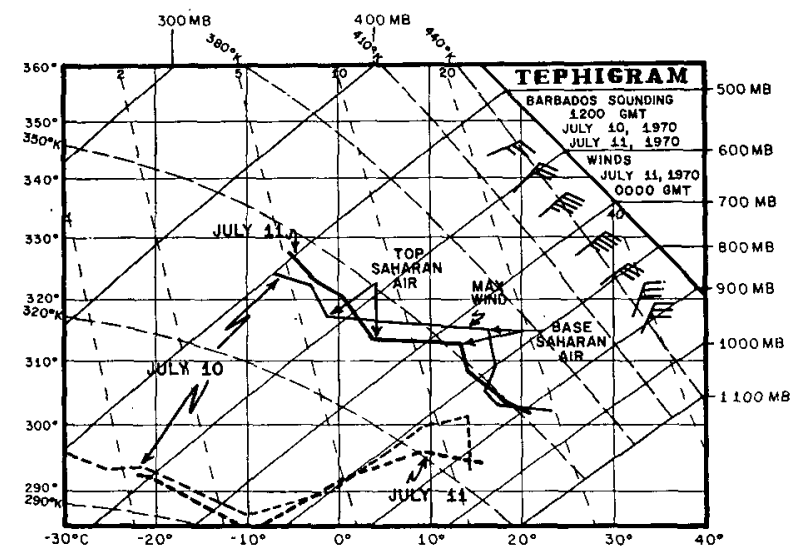

FIG. 16. Soundings made at Barbados, 10-11 July 1970 The vertical wind profile for an intermediate time is shown at the right.

${ }^{5}$ The anticyclonic rotation of the dust plume advancing westward behind a travelling disturbance is clearly depicted in a film loop made from a sequence of ATS-III satellite pictures for 1 July 1969. This incident is discussed in greater detail in a subsequent section of this paper. 

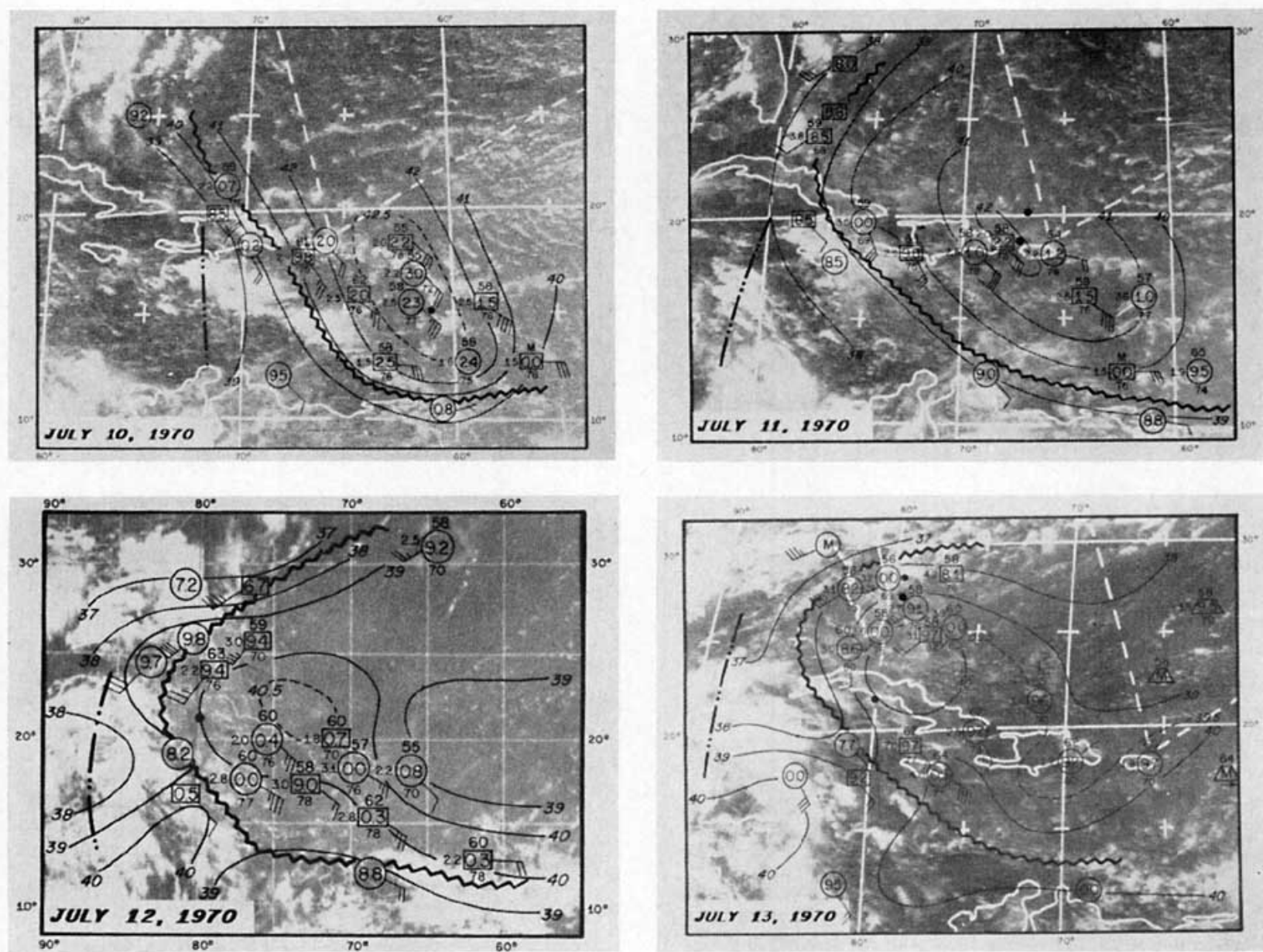

FIG. 17. ATS-III satellite photographs of the Caribbean, 10-13 July 1970 (a-d, respectively), upon which are superimposed the 1200 GMT sounding data and isotherms of the $700-\mathrm{mb}$ potential temperatures (solid contours). The coding of the $700-\mathrm{mb}$ potential temperature, mean mixing ratio in the Saharan air, and height of the base and top of the Saharan air is identical to that in Fig. 12 The winds, however, are taken relative to the moving system (16 kt westward) and are plotted only where there was a definable wind maximum in the 850-500 mb layer; the flow, therefore, refers to the level of the middle-level (Saharan air) jet. Square station symbols signify that 12 -hr off-time data have been plotted $3.2^{\circ}$ of longitude east (or west) of the station to account for the displacement of the system. Trapezoidal station symbols indicate aircraft observations. The position of the dust front (the serrated border) separates Saharan from non-Saharan air (see Fig. 14). The easterly wave axis is also indicated by the dash-dotted line. The small filled circles signify ship or land observations where haze was reported in the presence of horizontal visibility less than $10 \mathrm{mi}$.

that there was no significant mixing between the air within the Saharan layer and the low-level maritime air which had not recently passed over a land mass.

In contrast, at Miami, the ground-level atmospheric dust loading and turbidity rose dramatically (to 78 $\mu \mathrm{g} \mathrm{m}^{-3}$ and over 0.3 , respectively) and the radon concentration tripled following the arrival of the dust plume and the onset of heavy haze on the 13 th. On the afternoon of the 13 th, the RFF aircraft $39 \mathrm{C}$, flying on a cloud seeding mission for the Experimental Meteorology Laboratory, NOAA, encountered suppressed conditions over the Florida Everglades. Observers reported an unusually dense red-brown haze which had a distinct top near $580 \mathrm{mb}$. The sounding produced by the aircraft's ascent to the $480 \mathrm{mb}$ is shown in Fig. 18; the top of the Saharan air layer is clearly discernible at $580 \mathrm{mb}$, in agreement with the reported height of the

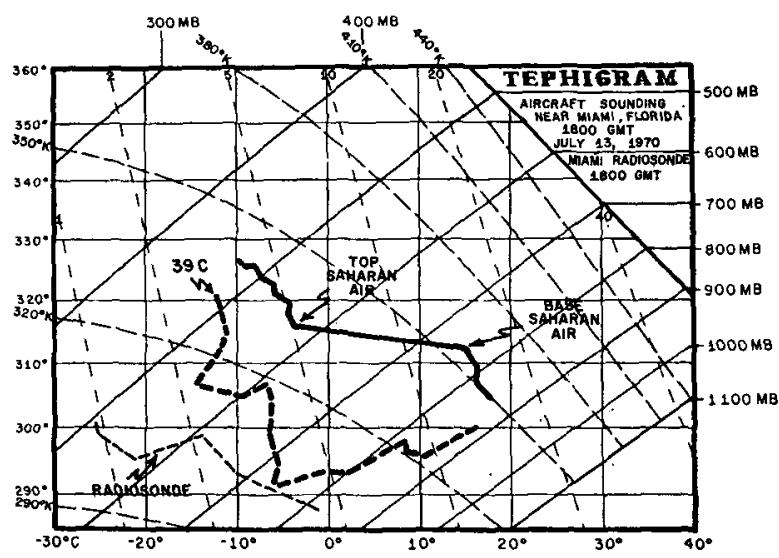

FIG. 18. Sounding made by DC-6 aircraft ascending just west of Miami and a portion of the dewpoint sounding from the Miami radiosonde, 13 July 1970. 


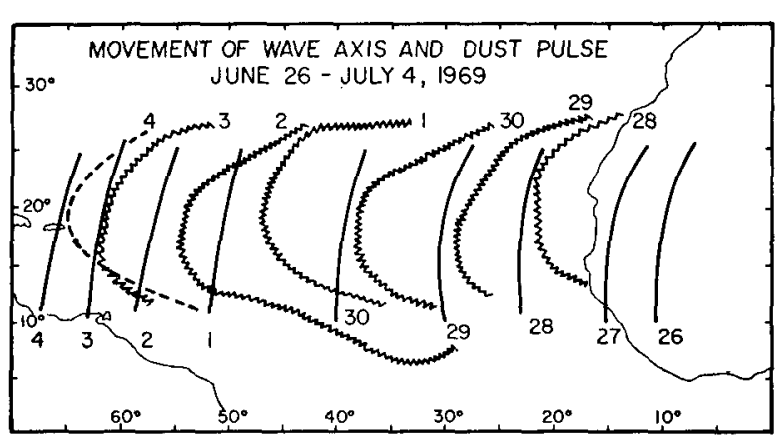

FIG. 19. Movement of wave axis and dust pulse, 26 June-4 July 1969. Positions of the leading edge of the dust pulse were determined from ATS-III satellite photographs; the placement of the wave axis was determined from the position of the apex of the "inverted V" on the photograph (see text). Extensive cloud cover west of the Antilles made it difficult to follow the progress of the dust plume after 3 July.

haze top. An isentropic layer $(\theta \approx 40 \mathrm{C})$ is visible between 580 and $760 \mathrm{mb}$, below which the clouds are obviously being suppressed by the warm base of the layer.

It should be pointed out, in the various aircraft soundings we examined (e.g., Figs. 5, 7 and 18), that the mixing ratio was found to be almost unchanging with height throughout the Saharan isentropic layer; this was not always the case with the conventional soundings (Figs. 6, 9, 16 and 18, for example). This discrepancy is probably attributable to the radiosonde hygristor which, because of its poor response time (Morressey and Brousaides, 1970), is incapable of recording the sharp transition between the moist mixed layer and the dry conditions above the base of the Saharan air. In addition, the radiosonde hygristor may seriously underestimate the true moisture content of the layer once it has come into equilibrium with the new dry environment above the inversion (Morressey and Brousaides, 1970).

\section{c. Further evidence for the large-scale transport of African dust}

Generally, parcels of dust-laden air over the ocean are visible in satellite photographs only during the first few days of the transit across the Atlantic. By the time the large-scale pulse of dusty air has entered the western Atlantic, estimates of position and areal extent based on photographs are somewhat ambiguous and must be verified by soundings showing the presence of Saharan air aloft; diagrams such as Fig. 14 showing the progress of dust fronts are composited in this manner. An exception is the dramatic series of ATS-III satellite photos which show the progress of a dust pulse from the time it leaves the coast of Africa on 28 June 1969 until it reaches the Leeward Islands on 4 July. ${ }^{6}$ The positions shown in Fig. 19 delineate the forward edge of the areas of greyish "smudge" which we find to be

\footnotetext{
${ }^{6}$ See Footnote 5.
}

characteristic in photos of regions where there is a dense dust haze. Although only the dust front is indicated in the figure, the photos clearly show that the entire equatorial Atlantic from $10-25 \mathrm{~N}$ is covered with dust for several days during early July. Unfortunately, the disturbance entered the BOMEX area during a rest interval between the third and fourth periods; consequently, there are no airborne dust measurements available. On 3 July the dust load at Barbados, situated at the southernmost edge of the plume, increased sharply (Fig. 1) and remained relatively high for several days (except for the 5 th when rainfall temporarily reduced the dust concentration). The position of the forward edge of the plume became diffuse on the satellite photographs after 4 July because of increased cloud cover west of $65 \mathrm{~W}$. However, high concentrations of dust were measured at Puerto Rico on 5 and 6 July (Volz, 1970) following the passage of this disturbance.

Perhaps the strongest evidence supporting our belief in a common African origin for the airborne dust collected during episodes such as these is that the mineralogy of the dust collected in hazy areas is uniform regardless of the location of the sampling site. In the event of July 1970 (discussed above) and during much of the summer, the $x$-ray diffraction spectra of the aerosol samples collected at Miami $(26 \mathrm{~N}, 80 \mathrm{~W})$, Barbados $(13 \mathrm{~N}, 59 \mathrm{~W})$ and aboard the Discoverer are identical. In contrast the aerosol samples collected in Miami during the days prior to the arrival of an African air parcel consist almost entirely of calcite, as might be expected since there are large areas of exposed coral in this region and the soils are highly calcareous (Prospero and Carlson, 1971). The similarity in the composition of dust collected at Barbados and that collected aboard vessels off the coast of Africa during the summer months is a monotonously persistent phenomenon which we have noted from the inception of our shipboard aerosol sampling program during the summer of 1967 until the present; thus, there can be little question about the origin of this material.

\section{A model of the African dust plume}

A schematic flow pattern showing the movement of the African dust plume during the summer months is presented in Fig. 20. The model is a conceptual composite based on our general knowledge of the African circulation patterns and on a number of detailed studies of individual dust episodes such as the ones described in this paper.

The following features are incorporated in this model.

1) The low-latitude troughs identified as the axes of African wave disturbances which are often visible in the cloud pattern as an "inverted V" shape.

2) The dust front situated behind the trough, in the relatively cloud-free area.

3) The large-scale anticyclonic eddies behind the dust front at $600-700 \mathrm{mb}$. 
4) The low-level coastal flow of dust-free air from northern latitudes. (The portion of this flow having an overland trajectory may pick up small but significant quantities of dust.)

5) Dust-free low-level air from the southern latitudes sweeping inland and also in to the trough.

6) Upper level winds from the Sahara overriding the low-level winds along the coast.

The figure is not intended to convey the suggestion that African disturbances actually generate the dust pulses by bringing about an increased lifting of dust. However, it is highly probable that the alternate weakening and strengthening of the pressure gradient over Africa, caused by the cyclic passage of the disturbances, contributes to the cyclic variation in lowlevel wind speeds which, in turn, may produce a cyclic fluctuation in dustiness. Indeed, we have accumulated some statistical evidence which shows a weak correlation between the frequency of haze or dust observations over West Africa and the passage of a travelling disturbance. However, the weakness of this correlation may be due to the fact that in many instances, such as the ones described in this paper (see Fig. 13, for example), the surface observations fail to show any systematic variations in the day-to-day occurrence of dust, haze or visibility along the African coast.

It is also possible that the rainfall associated with the disturbance contributes to the fluctuating character of the dust loads by washing a large fraction of the dust from the air entering the disturbance, the Saharan air itself being modified by the cumulus mixing in these showers. In Fig. 17 a-d, for example, some to the trajectories of dusty air are shown to be passing close to the dense cloud cover to the east of the disturbance axis. Furthermore, although the Saharan air may serve as a strong suppressive influence on the convection, the intrusion of the airstream into an existing area of active cumulonimbus may result in a penetration of the Saharan inversion by the rising towers.

We believe that the pulsating nature of the Saharan airstream is associated with the periodic interruption of this flow due to the passage of travelling disturbances from Africa. This situation is depicted in Fig. 20 by the streamlines which show a split in the flow of heated Saharan air which is continuously leaving the continent and being exported to middle latitudes over Europe (Carlson and Ludlam, 1968) and toward the Caribbean. With the passage of a disturbance over the African coast, an amount of moist, dust-free oceanic air is advected northward behind the wave axis; consequently, the stream of Saharan air, which would otherwise flow westward in the tropics, is diverted to join the northward-moving airstream along the African coast. ${ }^{7}$ Conversely, the air immediately ahead of the wave axis in Fig. 20 would be drawn from the northern Atlantic

\footnotetext{
${ }^{7}$ The presence of Saharan air containing high dust concentrations has been observed over Northern Europe (Stevenson, 1969).
}

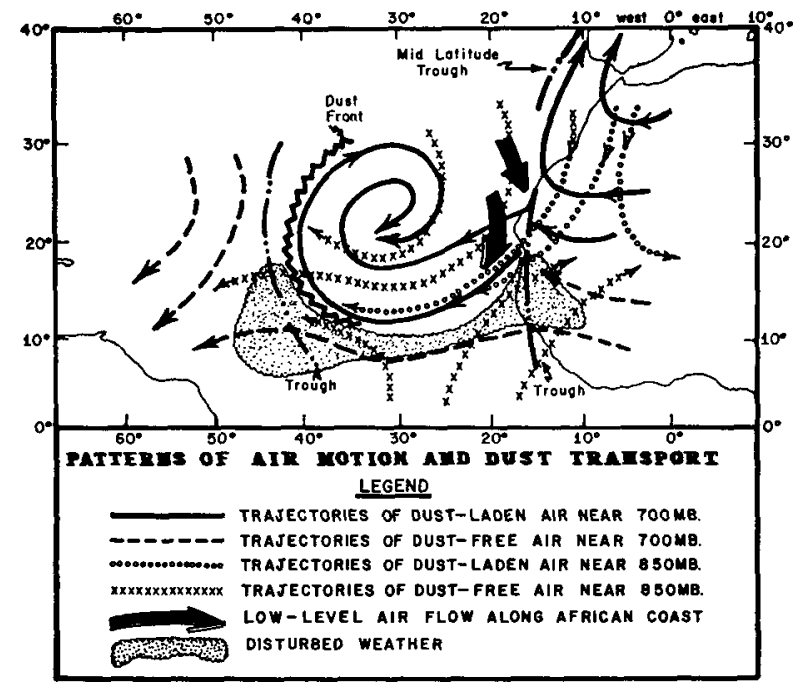

FIG. 20. Schematic model of air motions accompanying the movement of African disturbances and the associated dust pulses from Africa.

(either directly or on a relatively short overland route) rather than from the interior of the Sahara and, therefore, would be relatively low in dust and not as warm as the primary stream of Saharan air. ${ }^{8}$ Consequently, there is a strong temperature contrast established in the 600$800 \mathrm{mb}$ layer between the wave axis and the Saharan air on either side of the disturbance. In accordance with this temperature gradient the thermal wind relationship for geostrophic flow implies the existence of a warm anticyclonic cell located between the disturbances at middle levels and a jet-like character of the wind in the region of strongest temperature contrast. Indeed, on an even larger scale, the clockwise turning of the Saharan air toward the north along the entire west coast of Africa is associated with the warm Saharan anticyclone and a semi-permanent upper trough which lies along the coast of the Euro-African land mass in summer and which extends to quite low latitudes. Following the passage of the disturbance off the African Coast and the return of easterly flow, the westward advance of Saharan air is once again resumed at low latitudes.

\section{Radiational cooling and vertical motions in the dust layer}

Examination of the Caribbean analyses in Figs. 17 $a-d$ shows that the maximum potential temperatures in the Saharan air progressively decrease from 10 to 13 July at a rate of almost $1 \mathrm{C} d a y^{-1}$; this decrease is equivalent to a daily cooling rate of about $0.7 \mathrm{C}$ as measured in units of conventional, not potential, temperature. A net potential temperature change of

${ }^{8}$ African disturbances are known to be most intense in the vicinity of the African coast. The dust pulse, however, would remain despite later weakening of the disturbance. 


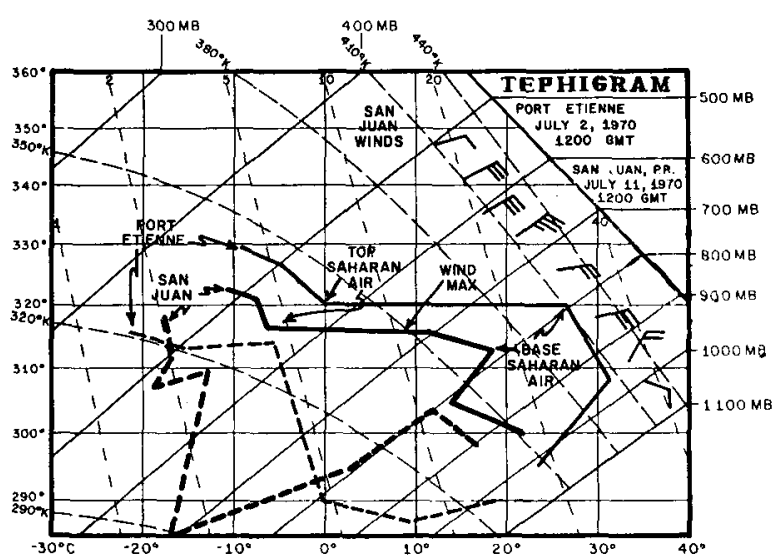

FIg. 21. Soundings for Pt. Etienne (Pt. Nouadhibou), Mauritania, 2 July 1970, and San Juan, Puerto Rico, 11 July 1970. The vertical wind profile for San Juan is shown at the right.

$3 \mathrm{C}$ is commonly observed when African soundings are compared with those made in the western Atlantic, implying a mean cooling rate of $0.5-0.7 \mathrm{C} \mathrm{day}^{-1}$ (see, for example, Figs. 6 or 21). In most of the events we have studied, Saharan air leaves Africa in July with a mean potential temperature of $43-44 \mathrm{C}$, a mixing ratio averaging between 2 and $4 \mathrm{gm} \mathrm{kg}^{-1}$, and a top at $540-560 \mathrm{mb}$. The air parcel arrives over the eastern Caribbean with a similar moisture content but with a potential temperature of about $40 \mathrm{C}$ (as in the two BOMEX cases described) and a top near $600 \mathrm{mb}$. The implied sinking motion of the Saharan air top is therefore about $50 \mathrm{mb}$ in $4-5$ days for a mean rate of $1 \mathrm{~mm} \mathrm{sec}^{-1}$. In the previously described case during July 1970, when an unusually warm and deep outbreak of Saharan air occurred, the warm center $(\theta \approx 43 \mathrm{C})$ was situated near the Antilles on the 10th (see Fig. 17). Assuming that this air had departed Africa on 5 or 6 July with a potential temperature of $46-47 \mathrm{C}$, its arrival over the Antilles on the 10th with a potential temperature of $43 \mathrm{C}$ would be compatible with a mean cooling rate of $0.7 \mathrm{C}$ day $^{-1}$ provided that the trajectory speed ${ }^{9}$ was about $30 \mathrm{kt}$. The implied sinking motion in this case was about $80-100 \mathrm{mb}$.

Cox (1969), London (1952), and others ${ }^{10}$ have found that the normal infrared cooling of the middle tropical troposphere is about $2 \mathrm{C}$ day $^{-1}$ under average weather conditions and perhaps a little less $(\sim 1.6 \mathrm{C})$ under clear skies. London's (1952) results indicate that the net solar absorption at middle levels in the tropics is about $0.65-0.8 \mathrm{C}$ day $^{-1}$ under widely varying cloud conditions. Therefore, the net cooling (net longwave radiation loss minus shortwave absorption) is likely to be $0.9-1.2 \mathrm{C}$ day $^{-1}$, a little larger than the $0.7 \mathrm{C}$ estimate which we

\footnotetext{
${ }^{9}$ It is important to note that the trajectory speed of the Saharan air parcel can be substantially greater than the forward motion of the leading edge of the dust pulse as suggested in Fig. 20.

${ }_{10}$ "Summary of findings of the Workshop on BOMEX Radiation and Particulate Investigations, 21-23 October 1970," Memo to participants.
}

obtain by simply observing the temperature change in the African dust plume during its oceanic transit. Anthes (1970), using Sasamori's (1968) longwave $\left(\mathrm{CO}_{2}\right.$ and water vapor) radiation model, has calculated in frared cooling rates of about $2 \mathrm{C} \mathrm{day}^{-1}$ for the mean sounding in the tropics and somewhat lower values for drier conditions. Using Anthes' program, we have made longwave radiation calculations based on several soundings such as the one shown in Fig. 21; our results show that for mixing ratios of $2-3 \mathrm{gm} \mathrm{kg}^{-1}$ in the isentropic layer, the net cooling was about $2.5 \mathrm{C} \mathrm{day}^{-1}$ at the base of the Saharan layer and about $2 \mathrm{C} \mathrm{day}^{-1}$ at the upper inversion, but was only about $1.6 \mathrm{C} \mathrm{day}{ }^{-1}$ averaged over the isentropic layer itself. Since the moisture distribution is so critical in these calculations it remains to be seen whether the peculiar temperature and humidity distribution in the Saharan air is more important than the actual aerosol content of the atmosphere in accounting for discrepancies between observation and measurement which may have been noted in regions of haze. ${ }^{11}$ Recent observations made during BOMEX show, however, that the albedo, longwave emission and shortwave absorption are all enhanced by the presence of the Saharan haze layer. ${ }^{12}$

The top of the Saharan air arriving in the area south and east of the principal potential temperature maxima shown in Figs. 17 a-d appears to have descended to about $600 \mathrm{mb}$. Along the northwestern fringes of the Saharan plume, however, the Saharan air top appears to be somewhat higher, possibly because the descending motion in the Saharan plume is being reversed in the northward-moving part of the flow pattern, particularly near the middle latitude frontal zone where the isentropic surfaces would slope upward toward the north. (No vertical motions should be inferred from the displacements of the base of the Sarahan layer which would rise gradually between Africa and the Caribbean in response to a deepening of the trade wind moist layer produced by small-scale convection over the ocean.)

\section{Concluding remarks}

In this paper we have attempted to show that pulses of warm, dust-laden air from the Sahara are commonly present over the northern equatorial Atlantic Ocean during the summer and early fall. These pulses appear to be generated near the African coast by an interruption in the westward transport of dusty Saharan air caused by the passage of travelling disturbances from equatorial Africa; after the disturbances have passed, the westward flow of dusty air from the interior of the Sahara is resumed. A significant feature of the dust pulse is its anticyclonic rotation and strong winds (often with a distinctive jet maximum near $650 \mathrm{mb}$ ) which necessarily exist in the presence of the strong horizontal

\footnotetext{
${ }^{11}$ See Footnote 10.

12 See Footnote 10.
} 
temperature contrast between the Saharan pulse and surrounding air masses. Because the Saharan air departs Africa only in a layer between approximately $850-550$ $\mathrm{mb}$, these pulses are shallow middle-level phenomena which are not easily recognizable on surface or highlevel wind charts. Nevertheless, in view of the largescale nature of the Saharan air anticyclone, the peculiarities of wind, temperature and atmospheric stability may well have important implications for the meteorology of the tropical Atlantic.

The dust concentration in the Saharan layer is high, being comparable to that in polluted areas over the United States (Blifford, 1970). Consequently, as far as aerosols are concerned, it is probably erroneous to think of this region in terms of a typical maritime atmosphere. We cannot state with any certainty what effect the presence of the dust has upon the meteorology of this region, although we have set forth an estimate of the atmospheric cooling in the Saharan air which may depend, in part, upon the optical and radiative properties of the dust. It also seems that in addition to modifying the radiation balance of the tropics the dust might play some secondary role in water vapor and ice nucleating processes.

Acknowledgments. We thank the Research Flight Facility (NOAA), particularly the crews of aircrafts $39 \mathrm{C}$ and $40 \mathrm{C}$, for their generous cooperation. We are especially grateful to Ann R. Prospero who participated in many of the flights and gathered much of the data presented here. We are indebted to Judge G. L. Taylor, Barbados, for the continued use of his land and residence for our operations and to R. Clarke, D. Moore and C. Sealy for their assistance in the Barbados studies. We are also indebted to personnel aboard the Discoverer for their diligence in making various measurements cited in the text.

We would also like to thank Dr. Harry Hawkins of NHRL for his encouragement and helpful criticisms. Mr. R. L. Carrodus drafted the figures.

A portion of this research was supported by the Office of Naval Research under Contract No. 4008(02) and the National Science Foundation under Grant GA-25916.

\section{REFERENCES}

Anthes, R. A., 1970: A diagnostic model of the tropical cyclone in isentropic coordinates. ESSA Tech. Memo. ERLTMNHRL-89, NHRL, Miami, Fla., 147 pp.

Blifford, I. H., Jr., 1970: Tropospheric aerosols. J. Geophy. Res., $75,3099-3103$.
Carlson, T. N., 1969a: Synoptic histories of African disturbances that developed into Atlantic hurricanes. Mon. Wea. Rev., 97, 256-276.

- 1969b: Some remarks on African disturbances and their progress over the tropical Atlantic. Mon. Wea. Rev., 97, 716-726.

effects of severe storms. Annual Summary Rept. No. 1, Grant AF-EOAR-64-60, Imperial College, London.

$\longrightarrow$, and - 1968 : Conditions for the formation of severe local storms. Tellus, 20, 203-226.

Cox, S. K., 1969: Observational evidence of anomalous infrared cooling in a clear tropical atmosphere. J. Atmos. Sci., 26, $1347-1349$.

Delany, A. C., A. C. Delany, D. W. Parkin, J. J. Griffin, E. D. Goldberg and B. E. F. Reimann, 1967 : Airborne dust collected at Barbados. Geochim. Cosmochim. Acta, 31, 885-909.

Flowers, E. C., R. A. McCormick and K. R. Kurfis, 1969: Atmospheric turbidity over the United States, 1961-1966. J. Appl. Meteor., 8, 955-962.

Frank, N. L., 1969: The "Inverted V" cloud pattern-an easterly wave? Mon. Wea. Rev., 97, 130-140.

Junge, C., 1963: Air Chemistry and Radioactivity. New York, Academic Press, $382 \mathrm{pp}$.

London, J, 1952: The distribution of radiation temperature change in the Northern Hemisphere during March. J. Meieor., 9, 145-151.

Morressey, J. F., and F. J. Brousaides, 1970: Temperature-induced errors in the ML-476 humidity data. $J$. Appl. Meteor., 9, 805-808.

Pearson, J. E., and G. E. Jones, 1966: Soil concentrations of emanating radium-226 and the emanation of radon-222 from soils and plants. Tellus, 18. 655-622.

Prospero, J. M., 1968: Atmospheric dust studies on Barbados. Bull. Amer. Meteor. Soc., 49, 645-652.

- , and T. N. Carlson, 1970: Radon-222 in the north Atlantic trade winds: Its relationship to dust transport from Africa. Science, 167, 974-977.

_- and - - 1971: Mineralogy of aerosols collected at Miami, Florida: Evidence for the frequent presence of African dust (Abstract) Trans. Amer. Geophys. Union, 52, 370.

—_, E. Bonatti, C. Schubert and T. N. Carlson, 1970: Dust in the Caribbean atmosphere traced to an African dust storm. Earth Planetary Sci. Letters, 9, 287-293.

Sasamori, T., 1968: The radiative cooling calculation for application to general circulation experiments. $J$. Appl. Meteor., 7, 721-729.

Servant, J., 1966: Temporal and spatial variations of the concentration of the short-lived decay products of radon in the lower atmosphere. Tellus, 18, 663-670.

Stevenson, C. E., 1969: The dust fall and severe storm of 1 July 1968. Weather, 24, 126-132.

Volz, F. E., 1969: Some results of turbidity networks. Tellus, 21, 625-630.

- -1970 : Spectral skylight and solar radiance measurements in the Caribbean: Maritime aerosols and Sahara dust. $J$. Atmos. Sci., 27, 1041-1047. 